\title{
ADAPTABILIDADE E ESTABILIDADE DE LINHAGENS EXPERIMENTAIS DE SOJA SELECIONADAS PARA CARACTERES AGRONÔMICOS ATRAVÉS DE MÉTODO UNI-MULTIVARIADO ( ${ }^{(1)}$
}

\author{
MARIA CLIDEANA CABRAL MAIA $\left({ }^{2}\right)$; NATAL ANTONIO VELLO $\left({ }^{3}\right)$; MAURISRAEL \\ DE MOURA ROCHA $\left({ }^{4}\right)$; JOSÉ BALDIN PINHEIRO $\left({ }^{3}\right)$; NELSON FONSECA DA SILVA JÚNIOR $\left({ }^{5}\right)$
}

\begin{abstract}
RESUMO
Esta pesquisa visou estudar a interação entre genótipos e ambientes ( $\mathrm{G} \times \mathrm{E}$ ), a adaptabilidade e estabilidade fenotípica, com o uso do modelo biométrico AMMI (Additive Main Effects and Multiplicative Interaction Analysis), para avaliação da produtividade de grãos de linhagens experimentais $\left(\mathrm{F}_{10}\right.$ e $\left.\mathrm{F}_{11}\right)$ de soja. O material envolveu três populações obtidas a partir de um dialelo parcial 4 x 4 com quatro genitores resistentes a insetos (IAC-100, Crokett, Lamar e D72-9601-1) e quatro cultivares adaptadas (BR-6, IAS-5, Davis, OCEPAR-4). Em $\mathrm{F}_{2}$ foram empregados três procedimentos distintos de seleção de plantas individuais: PCI, população formada a partir de plantas $\mathrm{F}_{2}$ obtidas com controle total de insetos; PRIM e PRIS formadas a partir de plantas $\mathrm{F}_{2}$ selecionadas para resistência a insetos mastigadores e sugadores respectivamente. De $F_{3}$ a $F_{11}$ foi praticada seleção entre progênies para produtividade de grãos e tolerância ao fotoperíodo. Foram desenvolvidos 24 experimentos delineados em blocos ao acaso com duas repetições subdivididas em conjuntos experimentais com testemunhas comuns, combinando as três populações e oito ambientes. Os ambientes (E1 a E8) combinaram dois locais (Anhembi, Areão), dois anos agrícolas (1999/2000, 2000/ 2001) e dois sistemas de manejo (controle intensivo de insetos ou CII e controle ecológico de insetos ou CEI). Os experimentos de 1999/2000 e 2000/2001 incluíram, respectivamente, 40 e 20 linhagens de uma população. Com base na produtividade de grãos, concluiu-se: o método AMMI evidenciou como linhagens $\mathrm{F}_{11}$ estáveis e produtivas, 70\% da PCI, 65\% da PRIS e 55\% da PRIM; o local Anhembi destacou-se como de alta produtividade em todas as situações (três populações, dois anos e dois manejos; para as três populações, dentre os ambientes mais produtivos, o método AMMI destacou E1 (Anhembi, 1999/2000, CII) como de máxima estabilidade e E6 (Anhembi, 2000/2001, CEI) como de máxima instabilidade; para a capacidade de gerar linhagens superiores em adaptabilidade e estabilidade, sobressaíram-se os genitores IAC-100, D729601-1, BR-6, Davis e IAS-5; destaques especiais envolveram os cruzamentos do genitor IAC-100 com IAS-5, Davis, OCEPAR-4 e BR-6.
\end{abstract}

Palavras-chave: Glycine max, interação genótipo-ambiente, modelo AMMI, produtividade de grãos.

${ }^{1}$ ) Recebido para publicação em 20 de fevereiro de 2004 e aceito em 17 de fevereiro de 2006.

$\left({ }^{2}\right)$ Doutoranda em Agronomia pelo Programa de Pós-Graduação em “Genética e Melhoramento de Plantas, Escola Superior de Agricultura "Luiz de Queiroz", Universidade de São Paulo. Autora correspondente. E-mail: clideana@terra.com.br

$\left(^{3}\right)$ Departamento de Genética, ESALQ/USP, Caixa Postal 83, 13400-970 Piracicaba (SP).

( $\left.{ }^{4}\right)$ Embrapa Meio-Norte, Av. Duque de Caxias, 5650, B. Buenos Aires, 64006-220 Teresina (PI).

$\left(^{5}\right)$ Instituto Agronômico do Paraná, IAPAR, Caixa Postal 481, 86001-970 Londrina (PT). 


\title{
ABSTRACT \\ ADAPTABILITY AND STABILITY OF SOYBEAN EXPERIMENTAL LINES SELECTED FOR AGRONOMIC TRAITS AND INSECT RESISTANCE BY UNI-MULTIVARIATE METHOD
}

\begin{abstract}
This research studied the genotype $x$ environment interaction $(G \times E)$, the adaptability and phenotypic stability, by applying AMMI (Additive Main Effects and Multiplicative Interaction Analysis) method for evaluating seed yield of soybean lines in $\mathrm{F}_{10}$ and $\mathrm{F}_{11}$ generations. The material included three populations derived from a $4 \times 4$ partial diallel having four insect resistant parents (IAC-100, Crockett, Lamar, D72-9601-1) and other four parents (BR-6, IAS-5, Davis, Ocepar-4) which are early and have high seed yield. In the $\mathrm{F}_{2}$ generation it were used three procedures of plant selection: PCI, population derived from $\mathrm{F}_{2}$ plants under total control of insects; PRIM and PRIS, populations obtained from $\mathrm{F}_{2}$ plants after the selection for resistance to leaf-feeder (defoliating) and pod-feeder (stink bug complex) insects, respectively. From $F_{3}$ to $F_{11}$, it was performed selection for seed yield and photoperiod tolerance among progenies. Twenty four experiments were carried out in randomized complete block design with two replications subdivided in sets with common checks, by testing the three populations in eight environments (E1 to E8): two locations (Anhembi, Areão), two agriculture years (1999/2000, 2000/2001), and two management systems (CII: intensive control of insects; CEI: ecological control of insects). Each experiment included 40 and 20 lines from a population in 1999/2000 and 2000/2001 respectively. Based on seed yield, it was concluded that: the AMMI method evidenced large percentage of high yielding and stable lines in all three populations: 70\% in PCI, 65\% in PRIS, and 55\% in PRIM; the Anhembi location showed higher seed yield in all situations; for the three populations, among the environments with high seed yield, the AMMI method classified E1 (Anhembi, 1999/2000, CII) and E6 (Anhembi, 2000/2001, CEI) as the most stable and unstable environment respectively; lines with superior adaptability and stability originated from the following parents: IAC-100, D72-9601-1, BR-6, Davis, and IAS-5; outstanding biparental crosses occurred when the IAC-100 parent was crossed with IAS-5, Davis, OCEPAR-4 and BR-6.
\end{abstract}

Key words: Glycine max, genotype-environment interaction, AMMI model, seed yield.

\section{INTRODUÇÃO}

O cultivo extensivo da soja, contemplando ambientes diversificados, provoca uma resposta diferencial dos genótipos. Assim, a interação entre genótipos e ambientes ( $G \times E)$ representa aspecto relevante no contexto do melhoramento. O entendimento desse fenômeno torna-se imprescindível aos programas de melhoramento em que se buscam minimizar a inconsistência das características relacionadas à produtividade diante da variação ambiental, para recomendações mais acertadas (DuARte e Vencovsky, 1999). A interação também reduz a correlação entre os valores genotípicos e fenotípicos, diminuindo os ganhos genéticos com a seleção e complicando o trabalho dos melhoristas (NUNES, 2000).

Adaptações específicas de genótipos a ambientes podem fazer a diferença entre boa e excelente cultivar (GAUCH e ZOBEL, 1996). A interação G x E deve ser observada como um fenômeno biológico em suas implicações no melhoramento de plantas e não como simples efeito estatístico, cumprindo buscar a explicação evolutiva do evento se quiser tirar proveito de seus efeitos benéficos, bem como para contornar seus efeitos indesejáveis sobre a avaliação de genótipos e recomendação de cultivares. Diferenças em adaptação de genótipos em populações resultam, evidentemente, de diferenças de constituição gênica para os caracteres importantes nessa adaptação. A reação diferencial às mudanças ambientais pode ocorrer desde os mecanismos de regulação gênica até caracteres morfológicos finais (CHAVEs, 2001).

De acordo com Brasil (1990) e Duarte e ZiMMERMANN (1995), é preciso dispor de metodologias estatísticas adequadas para se estimar e explorar a interação, permitindo assim recomendações regionalizadas. As estimações da adaptabilidade e da estabilidade fenotípica podem ser feitas através do nível de resposta ao estímulo ambiental e da previsibilidade, isto é, a manutenção da produtividade perante ambientes diversos. Para tanto, com o procedimento AMMI (Additive Main Effects and Multiplicative Interaction Analysis) tem-se observado maior robustez do que nos métodos usuais existentes. Esse método, porém, não fornece a resposta ao estímulo ambiental. 
Métodos como a análise AMMI, que usam procedimentos multivariados, são mais complexos, além de necessitarem, comumente, de programas computacionais específicos. Os resultados gerados permitem, porém, que as interpretações sejam mais coerentes à realidade dos sistemas vegetais (Rosse, 1999). Nos últimos anos, tem ocorrido mudança importante na escolha dos modelos de análise da interação $(\mathrm{GxE})$, havendo substituição do enfoque tradicional univariado por métodos como a análise AMMi (Duarte e Vencovsky, 1999). R. W. Zobel e colaboradores em 1988 (citados por DUARTE e VeNCOVSKY, 1999) consideram que o método AMMI permite uma análise mais detalhada da interação $G$ $x \mathrm{E}$, garante a seleção de genótipos mais produtivos (capazes de capitalizar interações positivas com ambientes), propicia estimativas mais precisas das respostas genotípicas e possibilita uma fácil interpretação gráfica dos resultados da análise estatística através da representação dos dados em gráfico de dispersão multivariado (biplot). Nesse tipo de abordagem não se parte da premissa de que os desvios de aditividade decorrentes do ajuste dos efeitos principais (genótipos e ambientes) sejam inteiramente resultantes da interação G x E. Com efeito, tais desvios podem conter ruídos (variação não controlada). O descarte destes ruídos permitirá caracterizar melhor os fatores genéticos e ambientais realmente envolvidos na interação GxE e melhor estimar as respostas dos genótipos aos ambientes (DuARTE, 2001). De acordo com Crossa (1990), a principal finalidade da análise AMMI é selecionar modelos que expliquem o padrão relacionado à interação, desprezando-se os ruídos presentes nos dados e sem interesse para a seleção dos materiais genéticos.

O objetivo deste trabalho foi estudar a interação entre genótipos e ambientes e a estabilidade fenotípica, com uso do modelo biométrico AMMI para avaliação de linhagens experimentais de soja, com a finalidade de identificar genótipos superiores.

\section{MATERIAL E MÉTODOS}

O material (linhagens experimentais) foi desenvolvido pelo Setor de Genética Aplicada às Espécies Autógamas do Departamento de Genética da ESALQ/USP. Compreendeu três tipos de populações, obtidas de um dialelo parcial $4 \times 4$ envolvendo quatro genitores (IAC-100, Crockett, Lamar e D72-9601-1) resistentes a insetos e quatro cultivares adaptadas (BR-6, IAS-5, Davis, OCEPAR-4) com alta produtividade de grãos e precocidade (PINHEIRO, 1998).
$\mathrm{Na}$ geração $\mathrm{F}_{2}$, foram empregados três procedimentos de seleção de plantas individuais: (a) PCI (população com controle de insetos), originada da seleção para produtividade de grãos, no local ESALQ em Piracicaba, SP; (b) PRIS (população selecionada para resistência a insetos sugadores), obtidas pela seleção para resistência a insetos sugadores, em Mococa, SP (Estação Experimental do IAC) e (c) PRIM (população selecionada para resistência a insetos mastigadores), sintetizada após a seleção para resistência a insetos mastigadores (principalmente lagartas), em Campinas, SP. A partir da geração $\mathrm{F}_{3}$, os três tipos de populações foram desenvolvidos de maneira semelhante, por meio de experimentos realizados em locais diferentes, geralmente em cultivo atrasado (safrinha de outono - inverno). Em cada geração, promoveu-se seleção principalmente para produtividade de grãos e tolerância ao fotoperíodo.

Os experimentos desenvolvidos em 1999/2000 incluíram 120 linhagens experimentais $F_{10}$, (40 de cada população); os experimentos de 2000/01 envolveram 60 linhagens $F_{11}$, sendo 20 linhagens selecionadas em cada população. As repetições foram estratificadas em conjuntos experimentais, cada um deles com três testemunhas comuns: IAC-100, OCEPAR-4 e IAS-5.

Os 24 experimentos envolveram linhagens das populações e foram desenvolvidos em dois locais do município de Piracicaba, SP (Estação Experimental Anhembi e Fazenda Areão), dois anos agrícolas (1999/2000, 2000/2001) e dois sistemas de manejo (controle intensivo de insetos-CII e controle ecológico de insetos-CEI). Nos experimentos CII, promoveu-se a aplicação de inseticidas sempre que se detectaram insetos mastigadores e ou dois percevejos $/ \mathrm{m}^{2}$ de pano (método do pano de batida). Nos experimentos CEI, promoveu-se a aplicação de inseticidas apenas quando se observou a ocorrência de grande quantidade de danos nas folhas, causados por insetos mastigadores, ou quando a infestação natural atingiu quatro percevejos $/ \mathrm{m}^{2}$ de pano.

Todos os experimentos foram realizados no delineamento de blocos ao acaso, com duas repetições estratificadas em conjuntos experimentais $(20$ linhagens) com testemunhas comuns. Cada parcela foi composta por quatro fileiras de 5 metros de comprimento, espaçadas de 0,5 metros $\left(10 \mathrm{~m}^{2}\right)$. A área útil $\left(4 \mathrm{~m}^{2}\right)$ foi constituída pelos $4 \mathrm{~m}$ centrais das duas fileiras intermediárias. Avaliou-se a produtividade de grãos (gramas / parcela) mediante a massa dos grãos maduros (com 13\% de umidade), colhidos na área útil de cada parcela. 
Considerou-se como ambiente a combinação de ano, local e manejo. Assim, pela combinação dos dois locais (Anhembi e Areão) com os dois anos agrícolas (1999/2000 e 2000/2001) e os dois sistemas de manejo obtiveram-se oito ambientes distintos $(\mathrm{E} 1, \mathrm{E} 2, \ldots, \mathrm{E} 8)$ para cada tipo de população, quais sejam: [Anhembi-CII-2000 (E1), Anhembi-CEI-2000 (E2), Areão-CII-2000 (E3), Areão-CEI-2000 (E4), Anhembi-CII-2001 (E5), Anhembi-CEI-2001 (E6), Areão-CII-2001 (E7) e Areão-CEI-2001 (E8)]. A análise foi realizada com as médias das duas repetições em cada ambiente e população.

As análises de estabilidade e adaptabilidade fenotípica foram realizadas pelo método AMMI (ZOBEL et al. 1988) por meio dos procedimentos GLM e IML do SAS e programa descrito por DuARTE e VencovsKy (1999). A técnica combinou método univariado (análise de variância) para componentes principais e trata a interação multiplicativa desses fatores com base na análise multivariada por componentes principais e decomposição por valores singulares.

O modelo geral da análise foi de Duarte e VENCOVSKY,1999): segundo a equação:

$$
Y_{i j}=\mu+g_{i}+e_{j}+\sum_{k=1}^{p} \lambda_{k} \gamma_{i k} \alpha_{j k}+\rho_{i j}+\bar{\varepsilon}_{i j,} \quad \text { sendo: }
$$

$\mathrm{Y}_{\mathrm{ij}}$ : resposta média das repetições do i-ésimo genótipo no j-ésimo ambiente;

$\mu$ : a média geral;

$\mathrm{g}_{\mathrm{i}}$ : o efeito principal do genótipo "i" (i = 1,2,3,..,g);

ej: o efeito principal do ambiente "j" ( $j=1,2,3, \ldots, e)$;

$\overline{\mathcal{E}}_{i j \mathrm{ij}}$ : erro experimental médio; equação:

A interação GxE é modelada de acordo com a

$$
\sum_{k=1}^{p} \lambda_{k} \gamma_{i k} \alpha_{j k}+\rho_{i j} \text { (padrão + ruído), sendo: }
$$

$\lambda \mathrm{k}$ : valor singular do k-ésimo componente principal da interação (CPI), ( $\mathrm{k}=1,2, \ldots, \mathrm{p}$, em que p é o $\mathrm{n} .^{\circ}$ máximo de componentes principais estimáveis);

$\lambda$ ik: valor singular do i-ésimo genótipo no n-ésimo CPI;

$\alpha j \mathrm{j}$ : valor singular do j-ésimo ambiente no n-ésimo CPI;

pij: resíduo da interação G x E ou resíduo AMMI (ruído presente nos dados);

$p$ : número de CPI's retidos no modelo;

$k$ : raízes características não nulas, $\mathrm{k}=(1,2, \ldots, \mathrm{min}(\mathrm{g}-1, \mathrm{e}-1)$.

Para definição do número de eixos a serem retidos, a fim de explicar o padrão relacionado à interação, foram adotados os critérios propostos por GAUCH e Zobel (1988), levando em consideração a proporção da soma de quadrados da interação $\left(S Q_{G \times E}\right)$ acumulada até o n-ésimo eixo $\sum_{k=1}^{n} \lambda_{k}^{2} / Q_{\text {G(G.t) }}$. Dessa forma, o ponto de parada que determina a seleção do modelo de cada membro da família de modelos AMMI (AMMI0, AMMI1,..., AMMIn), foi obtido com base na significância dos testes FGollob, para os sucessivos termos da interação. $\mathrm{O}$ ruído $\mathrm{AMMI}$, reunindo os demais termos da $\left(S Q_{G x E}\right)$ (não retidos no modelo selecionado), também foi testado de maneira a assegurar o seu caráter desprezível (DUARTE e VENCOVSKY, 1999), através da significância do teste FR (Cornelius et al., 1992; Piepho, 1995): $F_{R, n}=\left(S Q_{G \times E}-\sum_{k=1}^{n} \lambda_{k}^{2}\right) /\left(f_{2} \cdot Q M_{\text {ErroMédio }}\right) ;$ com: $F_{2}=(\mathrm{g}-1-\mathrm{n})(\mathrm{a}-1-\mathrm{n})$

sendo: $\mathrm{f}_{2}$ - número de graus de liberdade associados a cada parcela da interação $G \times E$, com $n$ termos multiplicativos incluídos no modelo definido por Gollob (1968).

As respostas esperadas dos genótipos i nos ambientes $\mathrm{j}$, ou seja, as $\left(\hat{Y}_{i j}\right)$, foram determinadas pela equação:

$$
\begin{aligned}
& \hat{Y}_{i j}=\bar{Y}_{i .}+\bar{Y}_{. j}-\bar{Y}_{. .}+\sum_{k=1}^{n} \lambda_{k} \gamma_{i k} \alpha_{j k} \text { sendo: } \\
& \bar{Y}_{i .}: \text { média do genótipo "i"; } \\
& \bar{Y}_{. j}: \text { média do ambiente "j"; } \\
& \bar{Y}_{\text {... }} \text { :média geral. }
\end{aligned}
$$

\section{RESULTADOS E DISCUSSÃO}

A maioria dos coeficientes de variação experimental esteve abaixo de $20 \%$, o que indica boa precisão no controle das causas de variação de ordem sistemática dos ambientes experimentais, para a produtividade de grãos, um caráter quantitativo muito influenciado pelo ambiente. Observou-se empate relativo entre grupos testemunhas e linhagens, pois em 12 experimentos (seis com contrastes significativos), as testemunhas foram mais produtivas, enquanto nos outros 12 experimentos (também seis com contrastes significativos) as linhagens foram mais produtivas que as testemunhas.

A existência de variabilidade genética entre linhagens foi constatada tanto nas análises individuais quanto na análise conjunta. Além de linhagens dentro de populações, a análise conjunta das três populações detectou como significativos os efeitos principais entre os dois sistemas de manejo e entre os dois locais. Portanto, em termos de magnitudes relativas dos quadrados médios, os efeitos de locais e de manejos foram mais importantes que o efeito de anos agrícolas. Todavia, VencovsKy e TORRES (1988) enfatizam que, para o agricultor é mais importante que a cultivar seja estável ao longo dos anos. Também foi evidenciada a existência de 
interações entre os efeitos principais combinados dois a dois, com destaque para: populações $\mathrm{x}$ manejos, anos $x$ linhagens dentro de populações, manejos $x$ anos, manejos $\mathrm{x}$ locais e anos $\mathrm{x}$ locais. Todas essas cinco interações envolvem, no mínimo, um efeito principal significativo. Também foram detectadas interações significativas envolvendo três ou quatro efeitos principais: populações $x$ manejos x locais, manejos $\mathrm{x}$ locais $\mathrm{x}$ linhagens dentro de populações, populações $x$ anos $x$ locais; anos $x$ locais $x$ linhagens dentro de populações; manejos $\mathrm{x}$ anos $\mathrm{x}$ locais; manejos $x$ anos $x$ locais $x$ linhagens dentro de populações. É interessante notar a importância de manejos que foram significativos na análise conjunta, além de interagir de forma também significativa com a maioria dos efeitos principais. Portanto, o manejo diferenciado pode ser novo representante de ambientes nos experimentos dos programas de melhoramento de soja, além dos representantes tradicionais (locais, anos agrícolas, épocas de cultivo).

Na tabela 1, genótipos compreenderam vinte linhagens mais três testemunhas comuns para cada população (PCI, PRIS e PRIM), totalizando 69 genótipos. Efeito significativo da interação $\mathrm{G} \times \mathrm{E}$, foi detectado pelo teste F (Cochran, 1954). Obteve-se resposta significativa ao nível de $1 \%$ de probabilidade para os efeitos principais de genótipos (G), e de ambientes (E) e também para a interação $\mathrm{G} \times \mathrm{E}$. O efeito de ambientes E, seguido pelo efeito da interação resultou em maior contribuição para a variação dos tratamentos; o efeito de genótipos $(\mathrm{G})$ foi responsável pela menor parte dessa variação. Essa situação era esperada, uma vez que os ambientes foram escolhidos por serem bem contrastantes, enquanto os genótipos pesquisados são os remanescentes da seleção praticada entre plantas $F_{2}$ para tolerância a insetos e entre progênies $F_{3}$ a $F_{10}$ para produtividade de grãos.

As três populações foram geradas através de cruzamentos entre genitores divergentes para adaptabilidade, incluindo-se materiais bem adaptados às condições ambientais brasileiras e um grupo de materiais exóticos ou semi-exóticos detentores de genes para resistência a insetos. Vello (1985) comenta que, apesar do efeito negativo que os materiais exóticos possam exercer na média da população resultante de cruzamentos mistos (adaptados x exóticos), é possível obter genótipos superiores mesmo nesses cruzamentos, desde que o genitor exótico tenha boa adaptação ao ambiente de cultivo e caracteres de valor agronômico. Esse processo ocorre em vista da introdução nos materiais adaptados de alelos "novos" presentes nos genitores exóticos, fato que aumenta significativamente a variabilidade genética da população obtida de cruzamentos mistos dentro da espécie cultivada. É necessário selecionar os genitores exóticos para eliminar os genótipos que tenham alelos responsáveis por fenótipos indesejáveis ligados aos genes de interesse; outra justificativa seria o aumento da freqüência de alelos favoráveis na população, principalmente poligenes que controlam caracteres quantitativos como a produtividade de grãos e, dessa maneira, aumentar a probabilidade de obtenção de linhagens superiores no fim do programa (Rocha, 2002).

Usualmente, emprega-se o índice ambiental para classificar os ambientes, que é uma medida da qualidade ambiental, sendo classificados como favoráveis ou desfavoráveis em função do ordenamento das médias relativamente à média geral. A crítica mais forte à utilização deste critério diz respeito à associação do índice ambiental (variável independente na regressão) com a variável dependente, razão pela qual esta pesquisa sobre o efeito da interação foi efetuada pelo modelo AMMI.

De acordo com DuARTE (2001), a análise AMMI representa um dos potenciais instrumentos para que se possa aprofundar na compreensão dos fatores realmente envolvidos na manifestação da interação $G$ $x$ E. Para tanto, o método estima o efeito da interação GxE através da análise multivariada (análise de componentes principais - ACP e decomposição por valores singulares - DVS) para descrever o padrão subjacente aos dados de uma matriz de interação (G $x$ E), fazendo a decomposição da soma de quadrados da interação $G \times E\left(S Q_{G \times E}\right)$ em eixos ou componentes principais da interação (IPCA), sendo adotado aqui o critério "pos-dictivo" pelos testes $F_{\text {Gollob }}$ e $F_{R}$ apresentado por CoRnelius et al. (1992) e PIEPHO (1995), para seleção de modelos AMMI mais preditivos e parcimoniosos.

O primeiro eixo singular da análise AMMI retém a maior porcentagem de padrão e, com acumulação subseqüente das dimensões dos eixos, há diminuição na porcentagem de padrão e aumento de ruídos (GAUCH e ZoBEL, 1988). Idealmente, espera-se capturar grande parte do padrão estrutural da $\mathrm{SQ}_{\mathrm{GxE}}$ nos primeiros componentes (LAVORANTE, 2003). O estudo da interação foi realizado pela $\mathrm{ACP} ; \mathrm{SQ}_{\mathrm{GxE}}$ foi desmembrada em sete eixos ou IPCAs, apresentando significância ao nível de $1 \%$ pelo teste $\mathrm{F}_{\text {Gollob }}$ para o primeiro eixo (IPCA1); esse componente singular explica $39,85 \%$ daquela soma de quadrados, podendo ser considerado satisfatório por se tratar de caráter muito influenciado pelo ambiente (Tabela 2). Os demais eixos são incluídos no resíduo AMMI do último IPCA significativo, acumulando uma variação da $\mathrm{SQ}_{\mathrm{GxE}}$ predominantemente rica em variação não controlada (ruído). Assim, pelo critério de GolLob (1968), o modelo AMMI1 foi selecionado como aquele que melhor descreve o padrão inerente à interação G x E. 
Tabela 1. Identificação das linhagens (P1 a P20) das populações PCI (formada a partir de plantas $\mathrm{F}_{2}$ obtidas com controle total de insetos); PRIS (formada a partir de plantas $\mathrm{F}_{2}$ selecionadas para tolerância a insetos sugadores) e PRIM (formada a partir de plantas $\mathrm{F}_{2}$ selecionadas para tolerância a insetos mastigadores) e testemunhas

\begin{tabular}{|c|c|c|c|c|c|c|c|c|}
\hline Símbolo & Código PCI & \multicolumn{2}{|c|}{ N. ${ }^{\circ}$ Cruzamento } & Código PRIS & N. ${ }^{\circ}$ Cruzamento & Código PRIM & & Cruzamento \\
\hline $\mathrm{P} 1{ }^{1}$ & \multicolumn{2}{|l|}{ P-1-97-8001 } & 08-01 & P-2-97-8085 & 08-07 & P-3-97-8195 & & $08-11$ \\
\hline P2 & \multicolumn{2}{|l|}{ P-3-97-8146 } & 08-01 & P-2-97-8088 & 08-07 & P-3-97-8175 & & 08-11 \\
\hline P3 & \multicolumn{2}{|l|}{ P-2-97-8063 } & 08-02 & P-2-97-8091 & 08-07 & P-3-97-8178 & & 08-11 \\
\hline P4 & \multicolumn{2}{|l|}{ P-2-97-8064 } & 08-02 & P-2-97-8093 & 08-07 & P-2-97-8114 & & $08-12$ \\
\hline P5 & \multicolumn{2}{|l|}{ P-1-97-8004 } & 08-03 & P-2-97-8095 & 08-07 & P-2-97-8118 & & 08-12 \\
\hline P6 & \multicolumn{2}{|l|}{ P-1-97-8007 } & 08-03 & P-2-97-8096 & 08-07 & P-2-97-8119 & & $08-12$ \\
\hline P7 & \multicolumn{2}{|l|}{ P-1-97-8009 } & $08-03$ & P-3-97-8121 & 08-07 & P-3-97-8147 & & $08-12$ \\
\hline P8 & \multicolumn{2}{|l|}{ P-2-97-8067 } & 08-03 & P-3-97-8035 & 08-07 & P-1-97-8033 & & $08-13$ \\
\hline P9 & \multicolumn{2}{|l|}{ P-2-97-8068 } & 08-03 & P-3-97-8149 & 08-07 & P-3-97-8176 & & $08-13$ \\
\hline P10 & \multicolumn{2}{|l|}{ P-3-97-8172 } & 08-03 & P-1-97-8024 & 08-08 & P-1-97-8039 & & 08-15 \\
\hline P11 & \multicolumn{2}{|l|}{ P-2-97-8072 } & 08-04 & P-2-97-8100 & 08-09 & P-1-97-8043 & & $08-15$ \\
\hline P12 & \multicolumn{2}{|l|}{ P-2-97-8073 } & 08-04 & P-3-97-8173 & 08-09 & P-1-97-8051 & & $08-15$ \\
\hline P13 & \multicolumn{2}{|l|}{ P-3-97-8165 } & 08-05 & P-1-97-8026 & $08-11$ & P-1-97-8054 & & $08-15$ \\
\hline P14 & \multicolumn{2}{|l|}{ P-1-97-8010 } & 08-07 & P-2-97-8105 & 08-11 & P-1-97-8055 & & $08-15$ \\
\hline P15 & P-1-97-8012 & & 08-07 & P-2-97-8108 & $08-11$ & P-2-97-8056 & & $08-15$ \\
\hline P16 & P-1-97-8014 & & 08-07 & P-2-97-8009 & $08-11$ & P-1-97-8057 & & $08-15$ \\
\hline P17 & P-1-97-8016 & & 08-07 & P-3-97-8132 & $08-11$ & P-3-97-8122 & & $08-15$ \\
\hline P18 & P-1-97-8019 & & $08-07$ & P-3-97-8142 & 08-11 & P-3-97-8137 & & $08-15$ \\
\hline P19 & P-1-97-8022 & & $08-07$ & P-3-97-8151 & 08-11 & P-3-97-8158 & & $08-15$ \\
\hline P20 & P-2-97-8080 & & 08-07 & P-3-97-8154 & 08-11 & P-3-97-8136 & & $08-16$ \\
\hline N. ${ }^{\circ}$ Cruza & ento & & Genitores & & N. ${ }^{\circ}$ Cruzamento & $\mathrm{Ge}$ & nito & \\
\hline 08-01 & & BR-6 & $x$ & Crockett & 08-09 & Davis & $x$ & Crockett \\
\hline 08-02 & & BR-6 & $x$ & Lamar & $08-10$ & Davis & $x$ & Lamar \\
\hline 08-03 & & BR-6 & $x$ & IAC-100 & $08-11$ & Davis & $x$ & IAC-100 \\
\hline 08-04 & & BR-6 & $x$ & D72-9601-1 & $08-12$ & Davis & $x$ & D72-9601-1 \\
\hline 08-05 & & IAS-5 & $x$ & Crockett & $08-13$ & OCEPAR-4 & $x$ & Crockett \\
\hline 08-06 & & IAS-5 & $x$ & Lamar & $08-14$ & OCEPAR-4 & $x$ & Lamar \\
\hline 08-07 & & IAS-5 & $x$ & IAC-100 & $08-15$ & OCEPAR-4 & $x$ & IAC- 100 \\
\hline 08-08 & & IAS-5 & $x$ & D72-9601-1 & $08-16$ & OCEPAR-4 & $\mathrm{x}$ & D72-9601-1 \\
\hline Testemun & & & T1 (OCEPAR - & & AC-100) & & $(117$ & \\
\hline
\end{tabular}

( $\left.{ }^{1}\right)$ O sombreamento identifica linhagens e cruzamentos de maior destaque em cada população.

Apesar da porção relativamente pequena $(39,85 \%)$ de $S_{Q_{\text {GxE }}}$ explicada pelo primeiro eixo, espera-se capturar grande parte do padrão estrutural devido à interação $G \times$ E. Dessa forma, os escores de genótipos e de ambientes foram plotados, seguindo o modelo AMMI2 (Figura 1). Assim, estão acumulados $53,98 \%$ do padrão estrutural dos dados de produtividade de grãos, porcentagem significativa em se tratando desse caráter.

Conforme os critérios adotados, e de acordo com a figura 1, pode-se considerar como de alta estabilidade fenotípica para a população PCI, as linhagens P5, P11,
P10, P4, P12 e P15, em ordem decrescente, identificadas na tabela 1. Essas linhagens também foram mais estáveis que as testemunhas comuns; entre essas, T1 seguida de T2 foram as mais estáveis. Um segundo grupo de linhagens ainda pode ser identificado por ter um nível de estabilidade intermediária; assim, as linhagens com presivisibilidade média em ordem decrescente de estabilidade foram P6, P2, P18, P17, P8, P13, P1 e P20. O primeiro e segundo grupos de linhagens diagnosticadas como estáveis somam 14 linhagens ou $70 \%$ da população PCI. As linhagens P3, P9, P7, P19, P16 e P14 foram instáveis. 
Tabela 2. Autovalor $\left(\lambda_{\mathrm{k}}^{2}\right)$ e porcentagem da soma de quadrados acumulada (PA) por eixo singular. Análise conjunta de variância, incluindo o desdobramento da interação G x E para dados de produtividade de grãos $\left(\mathrm{kg} \mathrm{ha}^{-1}\right)$

\begin{tabular}{|c|c|c|c|c|c|c|c|}
\hline \multirow{2}{*}{$\begin{array}{c}\text { Eixos } \\
\text { Singulares }\end{array}$} & \multirow{2}{*}{$\lambda_{\mathrm{k}}^{2}$} & \multirow{2}{*}{ PA } & \multirow{2}{*}{ F.V. } & \multicolumn{2}{|c|}{ Cornelius } & \multicolumn{2}{|c|}{ Gollob } \\
\hline & & & & GL & FR & GL & $\mathrm{F}$ \\
\hline & & & Genótipos (G) & 68 & $1,82 * *$ & 68 & $1,82 * *$ \\
\hline & & & Ambientes (E) & 7 & $231,86 * *$ & 7 & $231,86 * *$ \\
\hline & & & GxE & 476 & $70,52 * *$ & 476 & $70,52 * *$ \\
\hline 1 & $2.883,74$ & 39,85 & IPCA1 & 402 & $1,03 *$ & 74 & $3,69 * *$ \\
\hline 2 & $1.023,05$ & 53,98 & IPCA2 & 330 & $0,96^{\mathrm{ns}}$ & 72 & 1,35 * \\
\hline 3 & 928,65 & 66,82 & IPCA3 & 260 & $0,87^{\mathrm{ns}}$ & 70 & $1,26^{\mathrm{ns}}$ \\
\hline 4 & 798,80 & 77,85 & IPCA4 & 192 & $0,79^{\mathrm{ns}}$ & 68 & $1,11^{\mathrm{ns}}$ \\
\hline 5 & 745,22 & 88,15 & IPCA5 & 126 & $0,64^{\mathrm{ns}}$ & 66 & $1,07^{\mathrm{ns}}$ \\
\hline 6 & 548,10 & 95,73 & IPCA6 & 62 & $0,47^{\mathrm{ns}}$ & 64 & $0,81^{\mathrm{ns}}$ \\
\hline \multirow[t]{2}{*}{7} & 309,31 & 100,00 & IPCA7 & 0 & & 62 & $0,47^{\mathrm{ns}}$ \\
\hline & & & Erro Médio & 693 & & & \\
\hline
\end{tabular}

FGollob : teste F de Gollob (1968). FR: Teste FR de Cornelius et al. (1992) e PiepHo (1995). **: significativo ao nível de probabilidade, p< 0,01. *: significativo ao nível de probabilidade, $\mathrm{p}<0,05 .{ }^{\text {ns }}$ : não significativo.

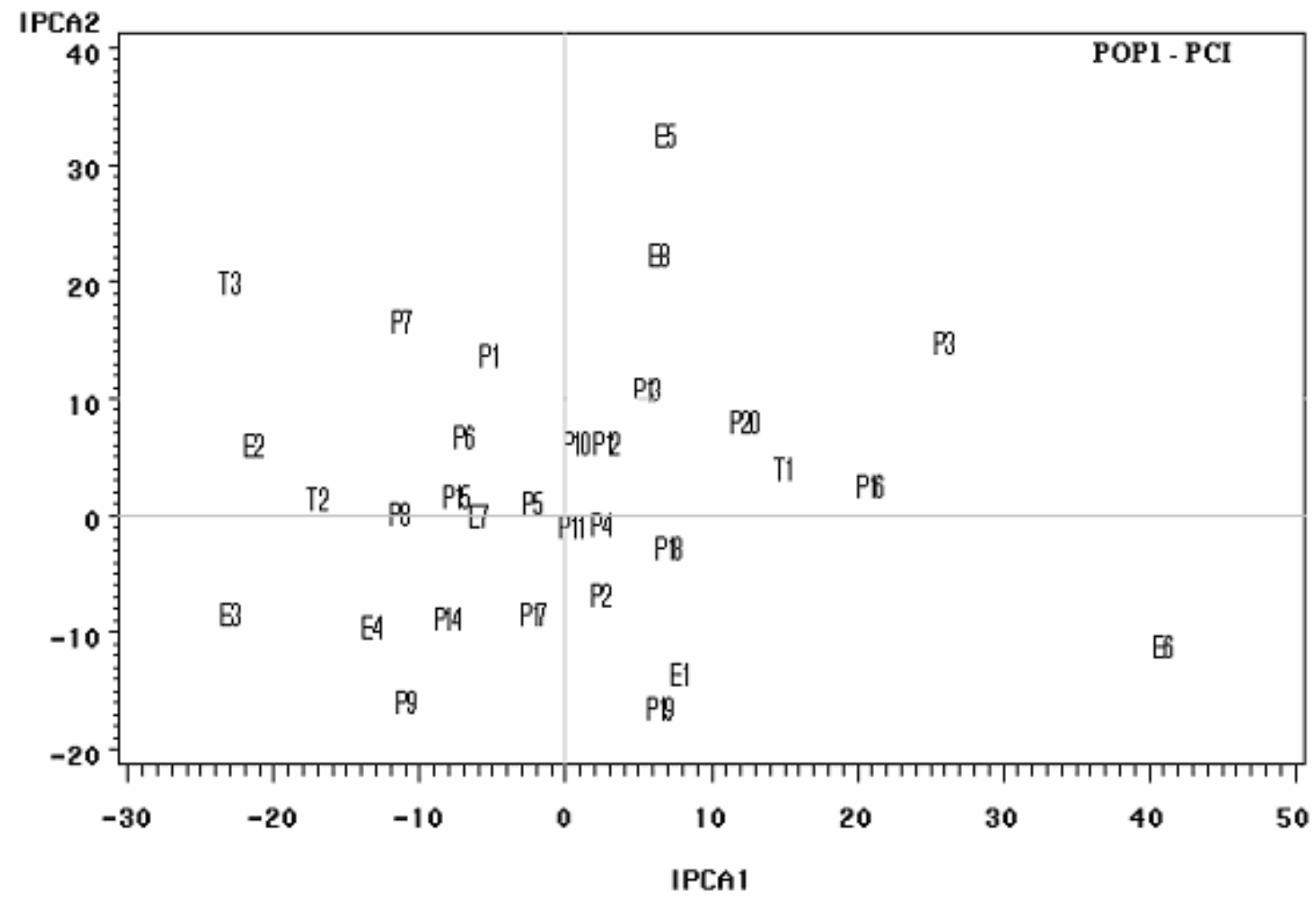

Figura 1. Escores (ICPA 1 e 2) de componentes principais do modelo AMMI, para produtividade de grãos (kg.ha-1 ${ }^{-1}$, de 20 linhagens (P1 a P20) da população PCI (População com Controle Total de Insetos), três testemunhas (T1 a T3) de soja e oito ambientes (E1 a E8). 
Na figura 1, observa-se que também os ambientes E1, E2, E4, E7 e E8, nessa ordem, foram os que menos influenciaram a magnitude da interação cruzada. Já os ambientes com mais alta instabilidade foram E6, E5 e E3.

As relações adaptativas podem ser facilmente percebidas num biplot AMMI observando-se os sinais dos escores para cada par de genótipos e ambientes. Assim, genótipos e ambientes com escores de mesmo sinal $(-,-$ ou,++$)$ devem interagir positivamente. Já aqueles com sinais opostos $(+,-)$ devem interagir negativamente (DUARTE e VENCOVSKY, 1999). De acordo com a figura 1, nas linhagens P5 e P15 verificou-se interação positiva com os ambientes E7 e E4; as linhagens P11 e P4 foram as de maior adaptabilidade diante da influência ambiental E1; nas linhagens P10 e P12 observou-se a capacidade de aproveitar bem a condição ambiental de E8. A segunda testemunha comum mais estável T2 adaptou-se bem aos ambientes E7 e E4. No conjunto de linhagens com estabilidade média, observou-se comportamento responsivo de P1 e P6 no ambiente E2; as linhagens P2 e P18 tiveram capacidade de explorar positivamente o efeito interativo do ambiente E1; P17 e P8 o fizeram com os ambientes E7 e E4; a linhagem P13 adaptou-se bem em E8.

Para a população PRIS, os genótipos que menos contribuíram para a interação cruzada, em ordem decrescente de estabilidade fenotípica foram P7, P10, P5, P9, P11, P20 e P3. No segundo grupo de linhagens com estabilidade mediana estão P2, P18, P13, P15, P19 e P14. Os dois grupos em conjunto representam $65 \%$ das linhagens que compõem a população PRIS. Na testemunha T1 notou-se o mais alto nível de estabilidade. Em outro grupo, contendo os genótipos mais instáveis, constatam-se as linhagens P16, P6, P8, P17, P12, P4 e P1 e as testemunhas T2 e T3 (Figura 2). O grupo de ambientes com estabilidade fenotípica mais pronunciada envolve E4, E5, E1, E7 e E8, em ordem decrescente de estabilidade fenotípica. Já dentre os que mais inflacionaram a interação $G x$ E aparecem E6, E2 e E3 (Figura 2).

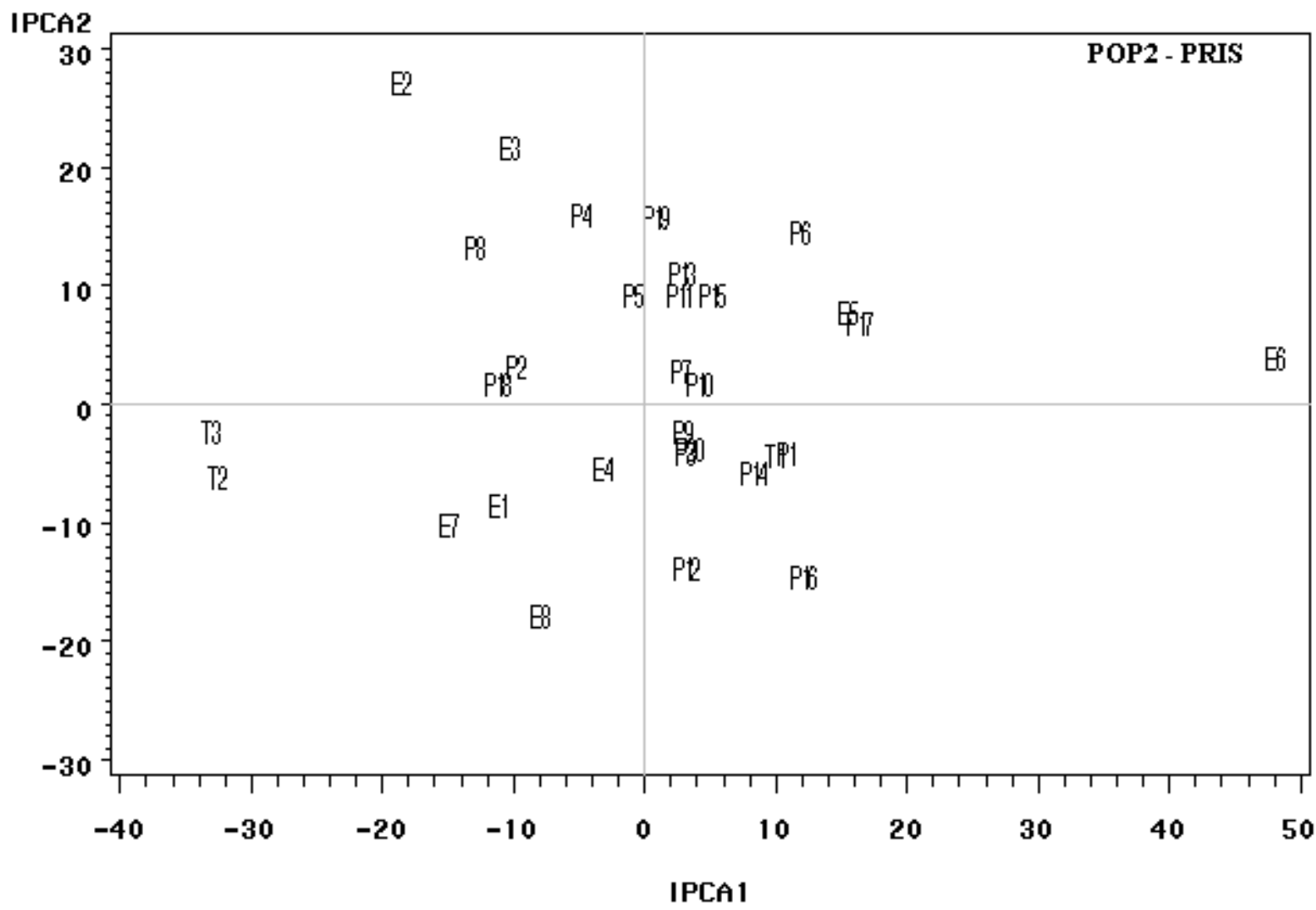

Figura 2. Escores (IPCA 1 e 2) de componentes principais do modelo AMMI, para 20 linhagens (P1a P20) população PRIS, três testemunhas (T1 a T3) de soja e oito ambientes (E1 a E8), para produtividade de grãos $\left(\mathrm{kg} . \mathrm{ha}^{-1}\right)$. 
As linhagens P7 e P11 indicaram sinergismo adaptativo na condição do ambiente E5. Já nas linhagens de presivibilidade média P13, P15 e P19, observou-se adaptação específica ao ambiente E5, enquanto a linhagem P18 combinou-se bem com os ambientes E4, E1 e E7. Para a testemunha mais estável (T1), não houve combinação adaptativa a nenhum ambiente (Figura 2).

Na população PRIM, as linhagens com estabilidade fenotípica mais alta, em ordem decrescente, foram P14, P7, P20, P15, P11 e P17. No grupo de magnitude média para previsibilidade estão P12, P19, P5, P16 e P4. Nesse caso, em $55 \%$ de linhagens da população PRIM observou-se estabilidade fenotípica apreciável. As mais instáveis foram P18, P8, P13, P2, P10, P3, P6, P9 e P1. As testemunhas comuns T1 e T2 são os genótipos com maior nível de estabilidade fenotípica (Figura 3).

O grupo de ambientes com menor variação foram agrupados em ordem decrescente de estabilidade fenotípica em: E4, E1, E7 e E8. Por outro lado, foram mais instáveis os ambientes E5, E6 e E2 (Figura 3).

Nas três populações, o ambiente E6 foi o de maior influência sobre a parcela da interação, pois o valor de seu escore está fora dos limites estabelecidos. Os ambientes menos variáveis, ou seja, os que menos contribuíram para a interação, no conjunto de populações, foram, E4, E1, E7 e E8. A testemunha T1 foi a de maior previsibilidade de comportamento em todos os ambientes.

No grupo de genótipos e ambientes da população PRIM com alta estabilidade fenotípica, indicam-se a linhagem P7 e a testemunha T1 com bom desempenho adaptativo diante do ambiente E8. Na linhagem P17 e na testemunha comum T2, verificaramse bom comportamento em combinação com o ambiente E7. No segundo grupo de linhagens, com estabilidade fenotípica média, tem-se P12 e P5 com relações de respostas positivas perante o ambiente E8; P19 e P4 foram bem associadas com E4 e E1; a linhagem P16 tirou proveito do estímulo ambiental de E7 como pode ser identificado na Figura 3.

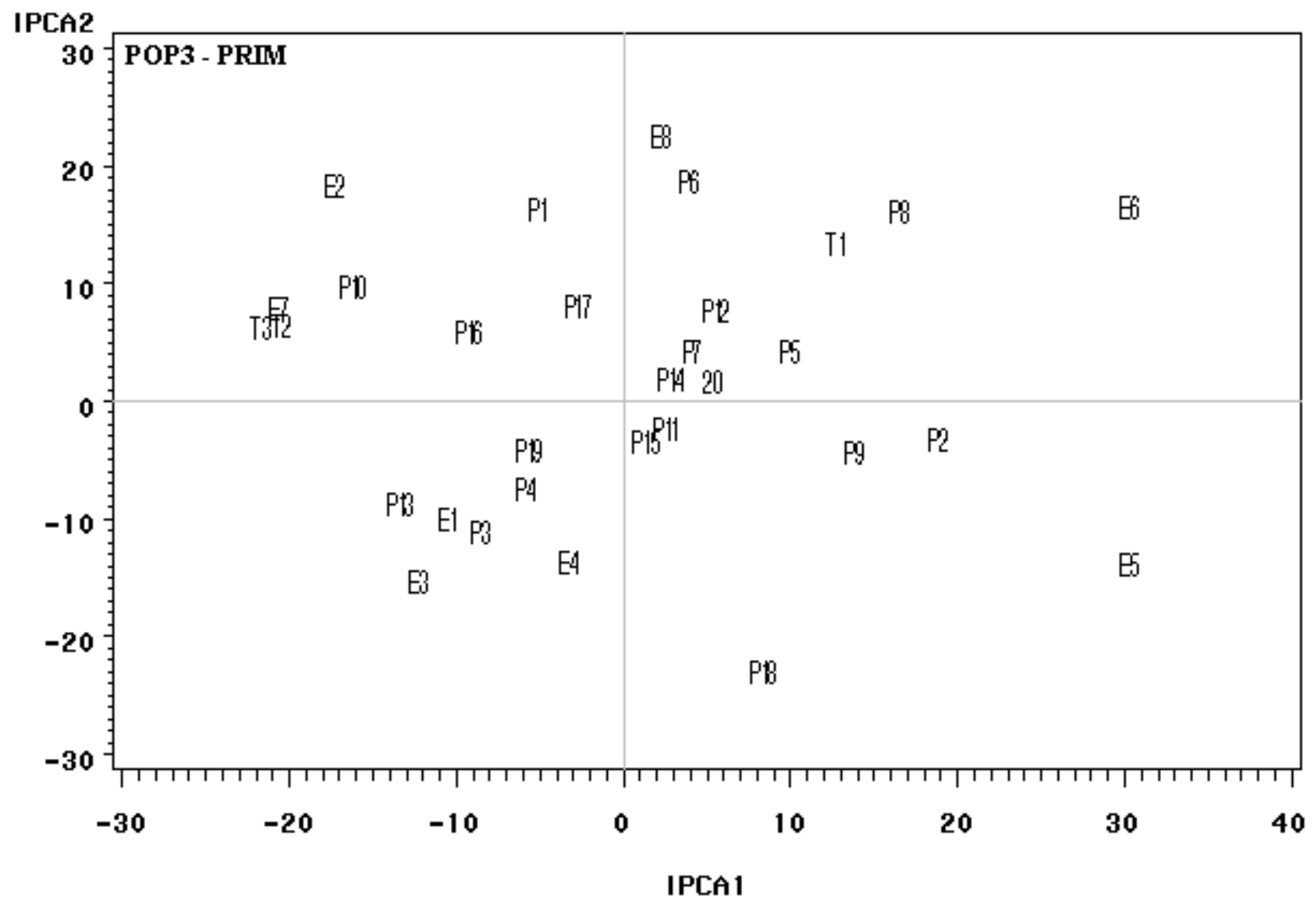

Figura 3. Escores (IPCA 1 e 2) de componentes principais do modelo AMMI, para 20 linhagens (P1 a P20) da população PRIM, três testemunhas (T1 a T3) de soja e oito ambientes (E1 a E8), para produtividade de grãos (kg ha-1). 
A PCI foi a população de maior número de linhagens com associações adaptativas. Aparentemente, está sendo evidenciada novamente uma certa associação negativa entre genes para tolerância a insetos e genes para produtividade e adaptação, uma vez que as outras duas populações (PRIS e PRIM) possivelmente têm freqüências maiores de alelos para tolerância a insetos em razão da seleção praticada entre plantas $\mathrm{F}_{2}$.

Outra abordagem que pode ser implementada via biplot AMMI1 é da maior importância para pesquisar a produtividade dos genótipos como resultado de seus componentes primários e secundários; caracteres agronômicos tais como resistência/tolerância a insetos estão incluídos neste contexto. $\mathrm{O}$ enfoque complementar às características de adaptabilidade e estabilidade fenotípica como o é a produtividade média dos materiais genéticos são imprescindíveis para recomendações de nova cultivar, que em última instância é o que mais interessa ao agricultor.

Nota-se pelo biplot AMMI1 (Figura 4), que das 20 linhagens da população PCI, em 17 (85\%) houve média de produtividade superior à média das testemunhas $\left(\mathrm{MT}=2.366 \mathrm{~kg} \mathrm{ha}^{-1}\right)$. Dentre essas linhagens, destacaram-se com interações relativamente baixas com os ambientes 13 linhagens (65\%), a saber: P20, P1, P10, P5, P2, P12, P4, P6, P11, P13, P8, P15 e $\mathrm{P} 18$, em ordem decrescente de produtividade. Os ambientes E1 e E2 sobressaíram-se quanto à produtividade e, ao mesmo tempo, à estabilidade fenotípica (Figura 4).

Na população PRIS (Figura 5), observaram-se também 17 linhagens com produtividade média superior à média das testemunhas $\left(\mathrm{MT}=2.373 \mathrm{~kg}\right.$ ha ${ }^{-}$ $\left.{ }^{1}\right)$. As linhagens que agregam as características desejáveis de estabilidade fenotípica e alta produtividade, em ordem decrescente de desempenho produtivo, foram as seguintes: P7, P9, P2, P13, P11, P10, P18, P19, P3, P20 e P5, constituindo 55\% das linhagens da população PRIS. Os ambientes E1 e E5 conciliaram altas produtividades e estabilidade fenotípica.

Na população PRIM (Figura 6), notam-se 16 linhagens $(80 \%)$, com valor superior à média das testemunhas $(\mathrm{MT}=2.502 \mathrm{~kg} \cdot \mathrm{ha}-1)$, reportando aos grupos com alta e média magnitude de estabilidade fenotípica, tem-se em ordem decrescente de produtividade P4, P16, P20, P17, P7, P5, P15. Para os ambientes estáveis, a população PRIM foi a de maior produtividade no ambiente E1, representando apenas $35 \%$ das linhagens da população.

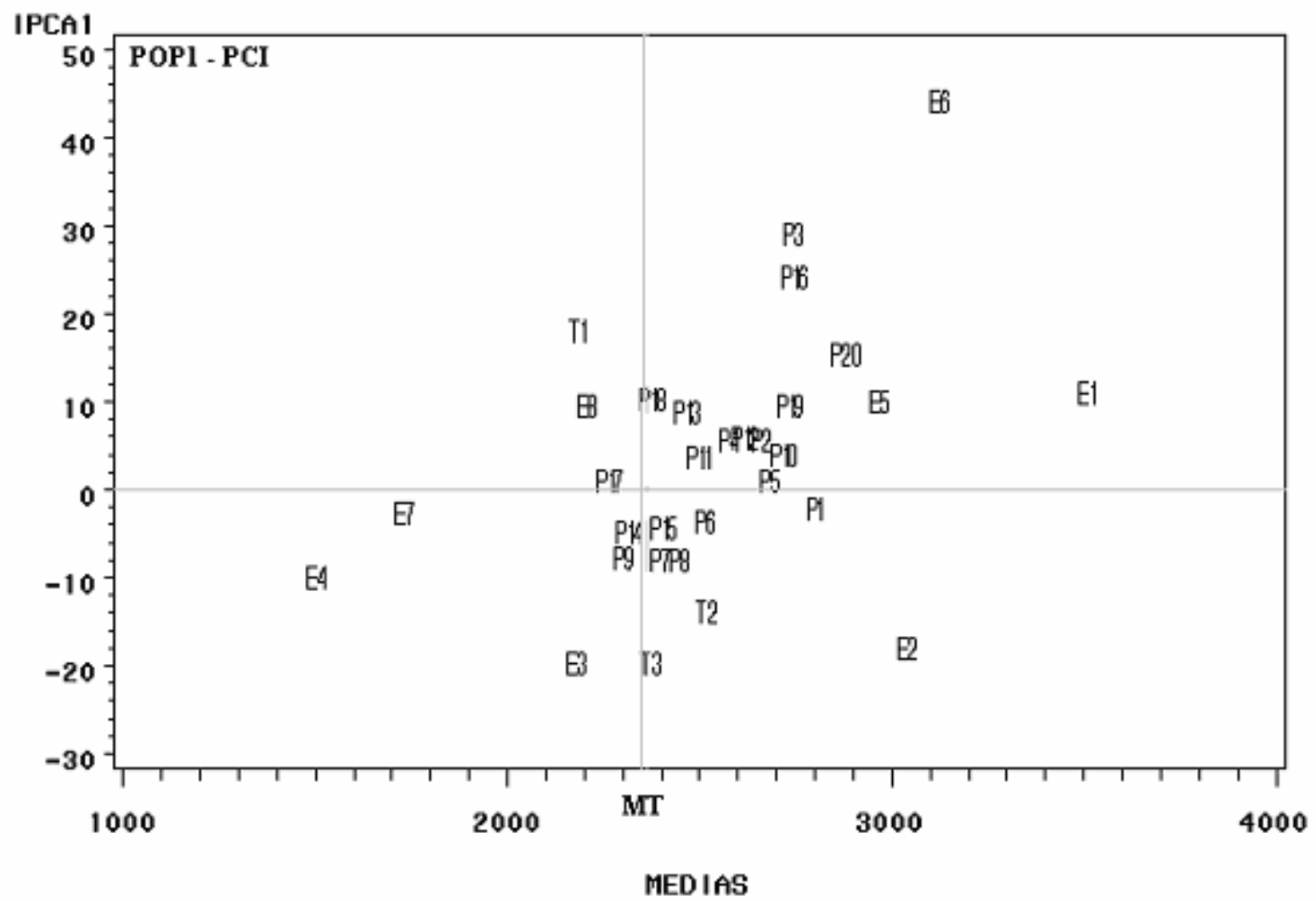

Figura 4. Biplot AMMI1 segundo os escores de componente principal- IPCA1 x médias de produtividade de grãos (kg ha $^{-1}$ ), para 20 linhagens (P1 a P20) da PCI (População com Controle Total de Insetos em $\mathrm{F}_{2}$ ), três testemunhas (T1 a T3) de soja e oito ambientes (E1 a E8). 


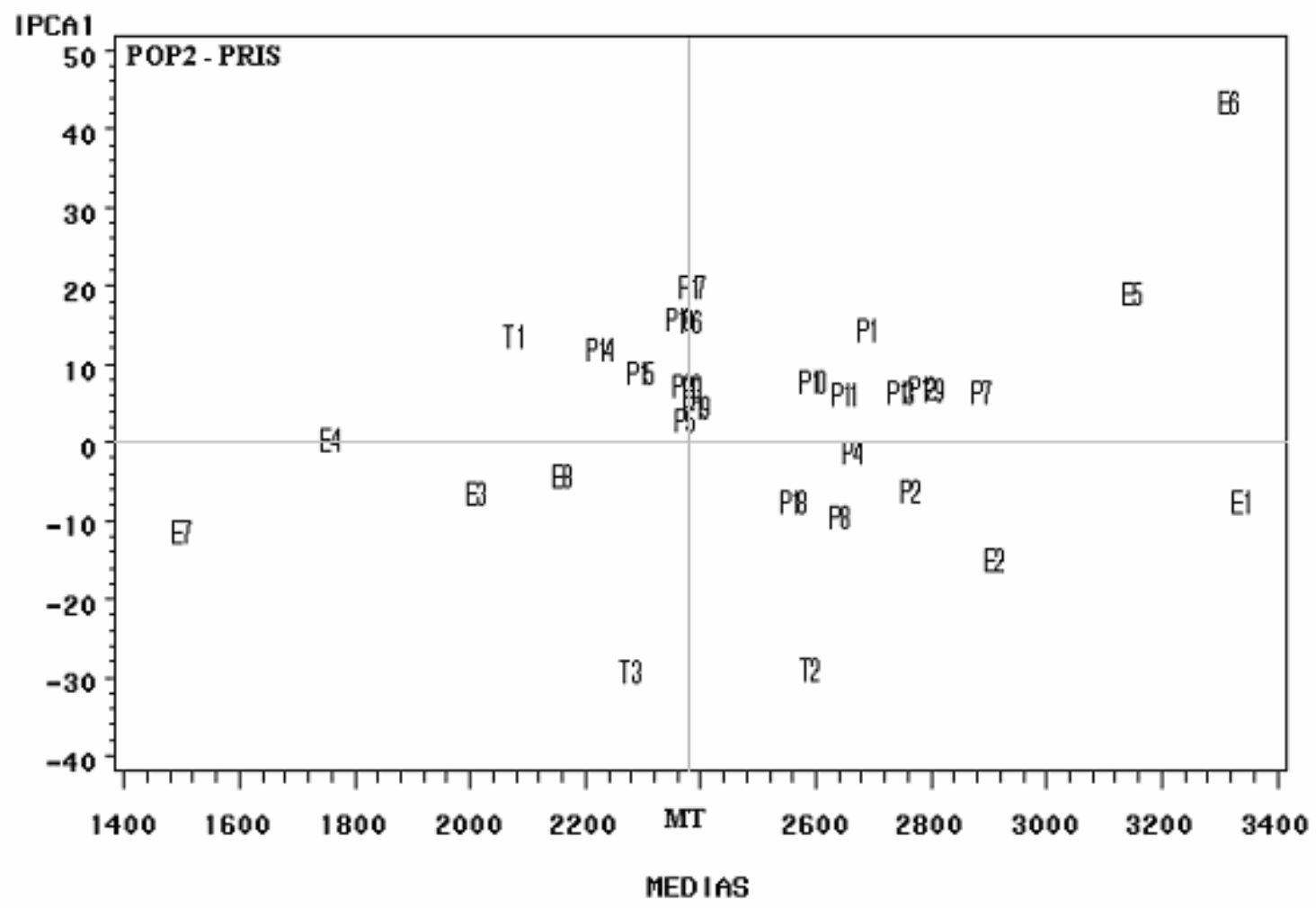

Figura 5. Biplot AMMI1 segundo os escores de componente principal - IPCA1 x médias de produtividade de grãos (kg ha $^{-1}$ ), para 20 linhagens (P1 a P20) da PRIS (População com seleção para Resistência a Insetos Sugadores em $\mathrm{F}_{2}$ ), três testemunhas (T1 a T3) de soja e oito ambientes (E1 a E8).

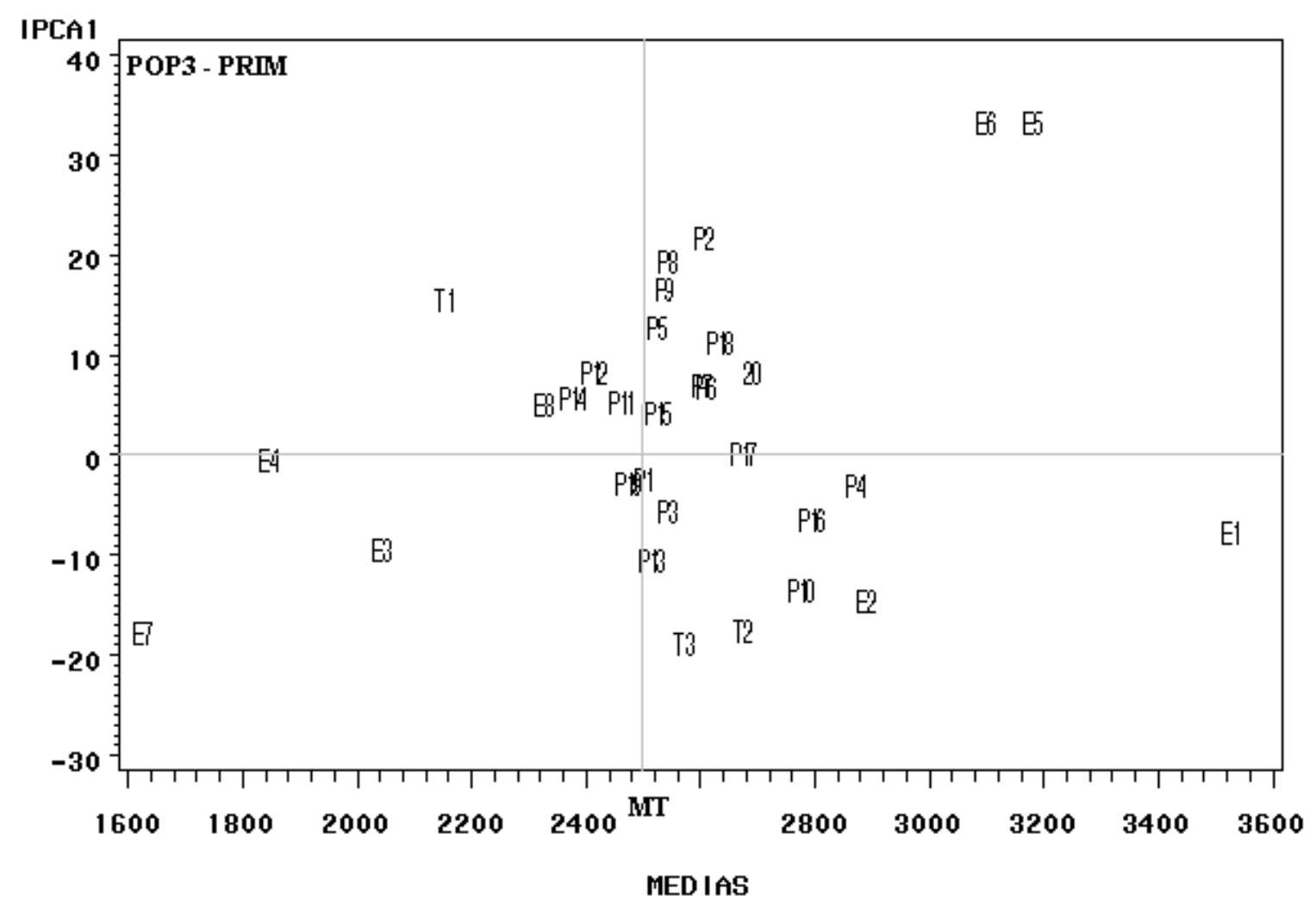

Figura 6. Biplot AMMI1 segundo os escores de componente principal - IPCA1 x média de produtividade de grãos $\left(\mathrm{kg}_{\mathrm{g}}\right.$ ha $\left.{ }^{-1}\right)$, para 20 linhagens (P1 a P20) da PRIM (População com seleção para a Resistência a Insetos Mastigadores em $\mathrm{F}_{2}$ ), três testemunhas (T1 a T3) de soja e oito ambientes (E1 a E8). 
A PCI seguida da PRIS foram as populações com maior número de linhagens com associações favoráveis de estabilidade fenotípica e produtividade de grãos. De acordo com a tabela 1 para a capacidade de gerar linhagens superiores em adaptabilidade e estabilidade, sobressaíram-se os genitores IAC-100, D72-9601-1, BR-6, Davis e IAS-5; destaques especiais envolveram os cruzamentos do genitor IAC-100 com os genitores IAS-5, Davis, OCEPAR-4 e BR-6.

\section{CONCLUSÕES}

1. O método AMMI evidenciou como linhagens $\mathrm{F}_{11}$ estáveis e produtivas $70 \%$ da PCI (População com Controle Total de Insetos em $\mathrm{F}_{2}$ ), 65\% da PRIS (População com Seleção para Resistência a Insetos Sugadores em $\mathrm{F}_{2}$ ) e $55 \%$ da PRIM (População com Seleção para Resistência a Insetos Mastigadores em F2).

2. O local Anhembi destacou-se como de alta produtividade em todas as situações (três populações, dois anos e dois manejos); para as três populações, dentre os ambientes mais produtivos, o método AMMI destacou E1 (Anhembi, 1999/00, CII) como de máxima estabilidade e E6 (Anhembi, 2000/01, CEI) como de máxima instabilidade.

3. Os genitores IAC-100, D72-9601-1, BR-6, Davis e IAS-5 originaram os maiores números de linhagens produtivas e estáveis; destaques especiais envolveram os cruzamentos de IAC-100 com IAS-5, Davis, OCEPAR-4 e BR-6.

\section{REFERÊNCIAS}

BRASIL, E.M. Comparação de métodos no estudo da interação de genótipos com ambientes em milho (Zea mays L.). 1990. 181f. Tese (Mestrado) - Universidade Federal de Goiânia UFG, Goiânia.

CHAVES, L. J. Interação de genótipos com ambientes. In: NASS, L.L.; VALOIS, A.C.C.; MELO, I.S.; VALADARES-INGLIS, M.C. (Ed.). Recursos genéticos \& melhoramento de plantas. Rondonópolis: Fundação MT, 2001. p.816-858.

COCRHRAN, W.G. The combination of estimates from different experiments. Biometrics, Alexandria, v.10, p.101-129, 1954.

CORNELIUS, P.L.; SEYEDSADR, M.; CROSSA, J. Using the shifted multiplicative model to search for "separability" in crop cultivar trials. Theoretical and Applied Genetics, Berlin, v. 84, n.1-2, p.161-172, 1992.

CROSSA, J. Statistical analyses of multilocation trials. Advances in Agronomy, San Diego, v. 44, p. 55-85, 1990.
DUARTE, J.B.; VENCOVSKY, R. Interação genótipos $\mathbf{x}$ ambientes: uma introdução à análise AMMI. Ribeirão Preto: Sociedade Brasileira de Genética, 1999. 60p. (Série Monografias, 9)

DUARTE, J.B. Aspectos gerais da interação genótipos $x$ ambientes com ênfase na formação de redes de avaliação (compact disc). In: CONGRESSO BRASILEIRO DE MELHORAMENTO DE PLANTAS, 1., Goiânia, 2001. Resumos... Goiânia: SBMP, 2001.

DUARTE, J.B.; ZIMMERMANN, M.J.O. Correlation among yield stability parameters in common bean. Crop Science, Madison, v.35, n.3, p.905-912, 1995.

GAUCH,H.G.; ZOBEL, R.W. Predictive and postdictive success of statistical analysis of yield trials. Theoretical and Applied Genetics, Berlin, v. 76, n.1, p.1-10, 1988.

GAUCH, H.G.; ZOBEL, R.W. AMMI analysis of yield trials. In: KANG, M.S.; GAUCH, H.G. (Ed.). Genotype-by-environment interaction. New York: CRC Press, 1996. 416p.

GOLLOB, H.F. A statistical model which combines features of factor analytic and analysis of variance techniques. Psychometrika, v.33, n.1, p.73-115, 1968.

NUNES, G.H.S. Interação genótipos $\mathbf{x}$ ambientes em eucalipto: implicações sobre a seleção e formas de atenuar seu efeito. 2000. 160 f. Tese (Doutorado)- Universidade Federal de Lavras.

PIEPHO, H.P. Robustness of statistical test for multiplicative terms in the additive main effects and multiplicative interaction model for cultivar trial. Theoretical and Applied Genetics, Berlin, v.90, n.3-4, p.438-443, 1995.

PINHEIRO, J.B. Seleção para caracteres agronômicos em diferentes épocas de cultivo, de populações de soja com resistência a insetos. 1998. 143 f. Tese (Doutorado) - Escola Superior de Agricultura "Luiz de Queiroz", Universidade de São Paulo, Piracicaba.

ROCHA, M.M. Seleção de linhagens experimentais de soja para adaptabilidade e estabilidade fenotípica. 2002. $173 \mathrm{f}$. Tese (Doutorado) - Escola Superior de Agricultura "Luiz de Queiroz", Universidade de São Paulo, Piracicaba.

ROSSE, L.N. Modelo de regressão não linear aplicado na avaliação da estabilidade fenotípica em plantas. 1999. 179p. Tese (Doutorado) - Escola Superior de Agricultura "Luiz de Queiroz", Universidade de São Paulo, Piracicaba.

VELLO, N.A. Efeitos da introdução de germoplasma exótico sobre a produtividade e relações com a base genética das cultivares de soja (Glycine max (L.) Merrill). 1985. $91 \mathrm{f}$. Tese (Livre-Docência) - Escola Superior de Agricultura "Luiz de Queiroz". Universidade de São Paulo, Piracicaba.

VENCOVSKY, R.; TORRES, R.A.A. Estabilidade geográfica e temporal de algumas cultivares de milho. In: CONGRESSO NACIONAL DE MILHO E SORGO, 16., Belo Horizonte, 1988. Anais... Belo Horizonte: EMBRAPA, CNPMS, 1988. p.294-300. 